\title{
Structured nursing follow-up: does it help in diabetes care?
}

Michal Shani ${ }^{1,2^{*}}$, Sasson Nakar ${ }^{1,2^{\wedge}}$, Alex Lustman ${ }^{1,2}$, Amnon Lahad $^{3}$ and Shlomo Vinker ${ }^{1,2}$

\begin{abstract}
Background: In 1995 Clalit Health Services introduced a structured follow-up schedule, by primary care nurses, of diabetic patients. This was supplementary care, given in addition to the family physician's follow-up care. This article aims to describe the performance of diabetes follow-up and diabetes control in patients with additional structured nursing follow-up care, compared to those patients followed only by their family physician.

Methods: We randomly selected 2,024 type 2 diabetic subjects aged 40-76 years. For each calendar year, from 2005-2007, patients who were "under physician follow-up only" were compared to those who received additional structured nursing follow-up care.
\end{abstract}

Main outcomes: Complete diabetes follow-up parameters including: HbA1c, LDL cholesterol, microalbumin, blood pressure measurements and fundus examination.

Results: The average age of study participants was 60.7 years, $52 \%$ were females and 38\% were from low socioeconomic status (SES).

In 2005, 39.5\% of the diabetic patients received structured nursing follow-up, and the comparable figures for 2006 and 2007 were $42.1 \%$ 49.6\%, respectively. The intervention subjects tended to be older, from lower SES, suffered from more chronic diseases and visited their family physician more frequently than the control patients. Patients in the study group were more likely to perform a complete diabetes follow-up plan: $52.8 \%$ vs. $21.5 \%$ (2005; $p<0.001)$ $55.5 \%$ vs. $30.3 \%$ (2006; $p<0.001$ ), 52.3\% vs. $35.7 \%$ (2007; $p<0.001)$. LDL cholesterol levels were lower in the study group only in 2005: 103.7 vs. $110.0 p<0.001$.

Conclusion: Subjects with supplementary structured nursing follow-up care were more likely to perform complete diabetes follow-up protocol. Our results reinforce the importance of teamwork in diabetic care. Further study is required to identify strategies for channeling the use of the limited resources to the patients who stand to benefit the most.

Keywords: Diabetes mellitus, Family physicians, Nurses, Primary care

\section{Background}

The United Kingdom Prospective Diabetes Study (UKPDS) demonstrated that improved glycemic control can prevent late complications of diabetes [1]. Prevention and early intervention of both microvascular and macro-vascular complications of Type 2 Diabetes Mellitus (T2DM) are important goals in diabetes care. Health care professionals

\footnotetext{
* Correspondence: michal.shani@gmail.com

Deceased

'Department of Family Medicine Central District, Clalit Health Service,

Rehovot, Israel

${ }^{2}$ Department of Family Medicine Sackler Faculty of Medicine, Tel Aviv

University, Tel Aviv, Israel

Full list of author information is available at the end of the article
}

invest time and effort in order to achieve glycemic control, and improve cardiovascular risk factors, reducing complications of diabetes.

Over the past two decades various protocols for health care delivery to diabetic patients have been suggested, so as to better utilize the professional skills of the healthcare team and improve the overall care of diabetic patients. A systematic review in 2001 found that structured recall or regular nurse contact, in addition to routine care, could bring about improved care for patients with T2DM [2].

In a previous study, patients who received automated calls with telephone nurse follow up, in addition to standard care, were more likely to perform annual cholesterol 
tests and poorly controlled diabetic patients showed an improvement in glycemic control compared to the control group [3]. Diabetic patients who were monitored by a nurse case manager, under the direction of a family physician, or an endocrinologist, had improved glycemic control within 12 months [4] and improved blood pressure, cholesterol and glycemic control at one year [5].

According to a Cochrane review, nurse case managers may improve patients' diabetic control over short periods of time, but the effects in the long term are not evident [6]. Additional nurse follow-up along with structured case management, in addition to regular care, appear to improve the process of diabetic follow-up, as well as improving diabetic control at one year, but little evidence exists as to the long term effectiveness of these programs.

Since 1995 a structured follow-up protocol for diabetic patients has been performed by nurses in primary care clinics of "Clalit Health Services" (CHS), the largest health maintenance organization (HMO) in Israel. This nurse follow-up is in addition to the family physician's regular follow-up [7]. The nurse visits include weight and blood pressure (BP) measurement, foot examination, referral for blood tests and fundus examination. In these visits, patients' adherence to medical treatment is reviewed. Diet, exercise and foot care are discussed with the patients. The nursing follow up is scheduled 2-4 times annually. Patients are seen by the nurse or referred to the nurse by the family physician, and the nursing follow-up is performed whilst maintaining both the doctor and nurse care. The follow up appointments were scheduled for all diabetic patients in this study, even though in real life this is impractical.

Despite the time, effort and resources that have been invested in providing supplemental nursing follow-up of diabetic patients, characteristics of the selected patients and follow up efficacies have not been evaluated.

Our aim was to describe the characteristics of the patients, and to compare performance of diabetes followup (glucose, cholesterol and BP control) in adult diabetic patients, between those with additional structured nursing care and those monitored only by their family physician.

\section{Methods}

The study was approved by the Hadassah Medical Organization's ethics committee.

\section{Study design}

A community based cohort study was performed in the Central District of Clalit Health Services (CHS) which serves over 500,000 patients. There were 29,854 diabetic patients listed on the CHS Central District register of chronic diseases during the study period.

\section{Setting}

Israel has mandatory health insurance, provided to all citizens and permanent residents by four HMOs. CHS is the largest $\mathrm{HMO}$ in Israel. It serves $54 \%$ of the population and more than $70 \%$ of diabetic patients. Patient records in CHS have been completely computerized for over a decade and an extensive healthcare database has been created. The demographic data is updated directly from the population registry of the Ministry of Interior. All laboratory tests are free of charge and sent to a central lab. The lab results are reported directly to the primary care physician, and to the patient's electronic medical file. The diagnosis of "diabetes mellitus" in the chronic disease register is estimated to be over $90 \%$ accurate [8]. The register is built by integrating information from patient files, hospital discharges, medication use and lab results.

CHS uses a passive capitation system where every patient is linked to one primary care physician. Every primary care physician is responsible for diabetes follow up for all patients on their list, including any patients seen in specialist diabetic clinics. Primary care clinics have both physicians and nurses and each has different responsibilities and tasks related to patient care. They work independently, in a coordinated manner, with the ultimate responsibility for care, being the physician's.

\section{Patients}

All Type 2 diabetic patients aged 40-76 years who were insured by CHS during the study period and who survived to the end of 2007, were considered eligible for the study. 2,024 diabetic patients were randomly selected from the eligible patients. Random selection of patients was done by using the control digit of the patient identity number which itself is assigned randomly.

The selected subjects were divided into two groups: patients who had physician follow-up only (control group) and patients who received additional structured nursing follow-up (intervention group). Specified separate groups were defined for the three consecutive years (2005-2007); we also compared patients who received structured nursing follow-up in all three study years to those who didn't complete a 3 year nursing follow-up protocol.

Structured nursing follow-up is performed by the clinic nurses, in all primary care clinics, as part of routine care. The patient is scheduled to meet the nurse 2-4 times a year for 20-30 minutes per visit. The nurses, in consultation with the physicians, manage the patient list and decide who to schedule for a follow-up appointment, according to the patient's needs and medical priorities. The follow-up includes a computerized check list of tasks to be performed and issues to be discussed with the patient. The appointment includes discussion and guidance in various subjects related to diabetes care, such as diet, 
use of medication, foot care and physical activity. The nurses are also required to verify that all recommended laboratory tests and referrals have been performed.

The main outcome measures in this study were the following parameters of diabetes follow up: BP measurement, LDL, urine microalbumin, HbA1C and fundoscopy (each of them at least once a year). Complete diabetes follow up was defined as performing all of these tests at least once during a calendar year. We also compared control of BP, LDL and HbA1c levels between subject groups.

Data were retrieved regarding patients' demographic, other chronic diseases, lab results, number of family physician visits and hospitalizations per calendar year. Patients with low socio-economic status (SES) were defined as those exempt from payments based on their income by the national insurance.

\section{Statistics}

The sample size needed to meet the study objectives was initially calculated to be 508 patients. This would enable detection of a $1 \mathrm{mg} \%$ difference in HbA1c, assuming an SD of 3 and assuming that $75 \%$ of patients were seen by the nurse, with a power of 0.9 and a $\mathrm{p}$ value of 0.05 . Since there were no strict guidelines controlling patient referral to the nurse and no previous data to rely on, we chose to sample four times this value.

Chi square and $t$-test were used for comparison of each variant. Logistic regression models were built to account for possible confounding, comparing the physician followup group to the intervention group for complete diabetic follow-up, achieving HbA1C goal (<7\%), LDL goal $(<100 \mathrm{mg} \%)$ and systolic BP goal $(<130)$.

Note that Clalit Health Service has a free choice of primary care physician. Each patient can choose his/her own primary care physician and his/her primary care clinic. During the follow-up years patients could change the clinic, their family physician or the primary care nurse, so we were unable to control for the hierarchical nature of the data (patients nested within physicians and physicians nested within clinics).

The analysis was done for each year separately and for all three years together. STATA 8.0 statistical software (Stata Corp. College Station, TX, USA) was used for statistical analysis.

\section{Results}

Of the 2,024 patients selected, 1,044 (51.6\%) were female. The average age was 60.7 years (range 40-76) and 760 (37.5\%) were from low SES. Table 1 demonstrates the patient characteristics for each of the study years.

In 2005, 801 diabetic patients (39.5\% of the 2,024 study participants) received structured nursing follow-up for diabetes. In 2006, this value rose to 852 patients (42.1\%)
Table 1 Patient characteristics

\begin{tabular}{|c|c|c|c|}
\hline & $\begin{array}{l}\text { Physician only } \\
\text { follow-up }\end{array}$ & $\begin{array}{l}\text { Supplemental nursing } \\
\text { follow-up }\end{array}$ & P-value \\
\hline 2005 & 1,223 & 801 & \\
\hline $\begin{array}{l}\text { Age (years, } \\
\text { mean } \pm \text { SD) }\end{array}$ & $59.8 \pm 9.0$ & $62.1 \pm 8.3$ & $<0.001$ \\
\hline Gender (\% men) & $47.3 \%$ & $50.1 \%$ & 0.231 \\
\hline Low SES (\%) & $33.5 \%$ & $43.6 \%$ & $<0.001$ \\
\hline Immigrant (\%) & $40.1 \%$ & $31.5 \%$ & $<0.001$ \\
\hline $\begin{array}{l}\mathrm{BMI}\left(\mathrm{Kg} / \mathrm{m}^{2}\right. \\
\text { mean } \pm \mathrm{SD})\end{array}$ & $29.7 \pm 5.2$ & $30.1 \pm 5.6$ & 0.092 \\
\hline $\begin{array}{l}\text { At least one } \\
\text { additional chronic } \\
\text { disease (\%) }\end{array}$ & $78.6 \%$ & $83.7 \%$ & $<0.001$ \\
\hline 2006 & 1,172 & 852 & \\
\hline $\begin{array}{l}\text { Age (years, } \\
\text { mean } \pm S D \text { ) }\end{array}$ & $59.8 \pm 8.8$ & $62.0 \pm 8.6$ & $<0.001$ \\
\hline Gender (\%men) & $48.1 \%$ & $48.8 \%$ & 0.755 \\
\hline Low SES (\%) & $33.0 \%$ & $43.8 \%$ & $<0.001$ \\
\hline Immigrant (\%) & $38.6 \%$ & $33.9 \%$ & 0.029 \\
\hline $\begin{array}{l}\mathrm{BMI}\left(\mathrm{Kg} / \mathrm{m}^{2}\right. \\
\text { mean } \pm \mathrm{SD})\end{array}$ & $29.8 \pm 5.3$ & $30.0 \pm 5.4$ & 0.350 \\
\hline $\begin{array}{l}\text { At least one } \\
\text { additional chronic } \\
\text { disease (\%) }\end{array}$ & $78.8 \%$ & $83.1 \%$ & 0.001 \\
\hline 2007 & 1,019 & 1,005 & \\
\hline $\begin{array}{l}\text { Age (years, mean } \\
\pm \text { SD) }\end{array}$ & $59.2 \pm 8.6$ & $62.2 \pm 8.7$ & $<0.001$ \\
\hline Gender (\% men) & $47.4 \%$ & $49.4 \%$ & 0.356 \\
\hline Low SES (\%) & $33.2 \%$ & $42.0 \%$ & $<0.001$ \\
\hline Immigrant (\%) & $41.4 \%$ & $31.8 \%$ & $<0.001$ \\
\hline $\begin{array}{l}\mathrm{BMI}\left(\mathrm{Kg} / \mathrm{m}^{2}\right. \\
\text { mean } \pm \mathrm{SD})\end{array}$ & $30.0 \pm 5.5$ & $29.8 \pm 5.2$ & 0.508 \\
\hline $\begin{array}{l}\text { At least one } \\
\text { additional chronic } \\
\text { disease (\%) }\end{array}$ & $78.6 \%$ & $82.6 \%$ & $<0.001$ \\
\hline $\begin{array}{l}\text { Complete } 3 \text { years } \\
\text { follow-up }\end{array}$ & 1,616 (79.8\%) & $408(20.2 \%)$ & \\
\hline $\begin{array}{l}\text { Age (years, } \\
\text { mean } \pm S D \text { ) }\end{array}$ & $60.0 \pm 8.8$ & $63.6 \pm 8.2$ & $<0.001$ \\
\hline Gender (\% men) & $52.6 \%$ & $49.3 \%$ & 0.295 \\
\hline Low SES (\%) & $35.0 \%$ & $47.8 \%$ & $<0.001$ \\
\hline Immigrant (\%) & 38.7 & $28.6 \%$ & $<0.001$ \\
\hline $\begin{array}{l}\text { BMl BMl }\left(\mathrm{Kg} / \mathrm{m}^{2}\right. \\
\text { mean } \pm \mathrm{SD})\end{array}$ & $29.8 \pm 5.4$ & $30.1 \pm 5.3$ & 0.419 \\
\hline $\begin{array}{l}\text { At least one } \\
\text { additional chronic } \\
\text { disease (\%) }\end{array}$ & $78.1 \%$ & $86.3 \%$ & $<0.001$ \\
\hline
\end{tabular}

and in 20071,005 patients (49.6\%) were enrolled in structured nursing follow-up care.

408 (20.1\%) patients received structured nursing followup through all three study years. Patients receiving 
structured nursing follow-up care, tended to be older, and a higher proportion of these patients had a low SES and were also diagnosed with additional chronic diseases.

Health resource utilization was higher among patients receiving structured nursing follow-up. Their hospita lization rate was higher $(13.7 \%$ vs. $10.5 \%$ in $2005 \mathrm{p}=$ $0.030,15.8 \%$ vs. $12.1 \%$ in $2006 \mathrm{p}=0.016$, and $16.8 \%$ vs. $11.2 \%$ in $2007 \mathrm{p}<0.001)$. However, these differences disappeared when the results were adjusted for patients' characteristics (age, gender, SES, immigrants, BMI, no. of chronic diseases). Physician visits (Table 2) were higher among the study group, and further adjustment for patients' characteristics did not influence these values.

Performance of complete diabetic follow-up is reported in Table 3. In each of the study years, complete diabetes follow-up protocol was more likely in the intervention group (2005: $21.5 \%$ vs $52.8 \%$, 2006: $30.3 \%$ vs $55 \%, 2007$ $35.7 \%$ vs $52.5 \%)$. Similarly, patients in the nursing followup group were more likely to have complete diabetic follow-up in all three years (26\% vs $10.4 \%$ ).

When potential confounders were taken into account, although the odds for complete follow-up were lower, they still remained over 1.4 times more likely in each of the follow-up years, for those receiving the nursing follow-up protocol (Table 4).

Minor differences between the groups were observed for systolic BP and HbA1C levels. More patients in the control group had controlled systolic BP. However, in the first two years of the study LDL levels were significantly lower in the nurse follow-up group (2005 110.0 vs $103.7 \mathrm{p}<0.001,2006110.8$ vs $105.7 \mathrm{p}<0.001$ ) (Table 5). When odds ratios were calculated for the likelihood of achieving treatment goals for LDL only, in the first year of the study, they improved in the nurse follow-up group. However, the improvement in 2006 was nullified after adjusting for potential confounding factors (Table 4).

\section{Discussion}

The follow-up and treatment of diabetic patients is complex and requires cooperation between both patient and health professionals, and between different health

Table 2 Number of family physician's visits per year (average \pm SD)*

\begin{tabular}{|c|c|c|c|}
\hline & $\begin{array}{l}\text { Physician only } \\
\text { follow-up }\end{array}$ & $\begin{array}{l}\text { Supplemental nursing } \\
\text { follow-up }\end{array}$ & P-value \\
\hline 2005 & $3.8 \pm 3.8$ & $6.8 \pm 4.6$ & $<0.001$ \\
\hline 2006 & $4.3 \pm 3.9$ & $7.3 \pm 4.9$ & $<0.001$ \\
\hline 2007 & $4.9 \pm 3.8$ & $7.2 \pm 5.0$ & $<0.001$ \\
\hline $\begin{array}{l}\text { Complete } \\
3 \text { years follow- } \\
\text { up average visits } \\
\text { per year }\end{array}$ & $5.0 \pm 3.4$ & $7.7 \pm 4.5$ & $<0.001$ \\
\hline
\end{tabular}

*The differences did not change when adjusted for patients characteristics (age, gender, SES, immigrants, BMI, no. of chronic diseases).
Table 3 Performance of complete diabetes follow-up* (\% of patients)

\begin{tabular}{llll}
\hline Year & $\begin{array}{l}\text { Physician only } \\
\text { follow-up }\end{array}$ & $\begin{array}{l}\text { Supplemental nursing } \\
\text { follow-up }\end{array}$ & P-value \\
\hline 2005 & $21.5 \%$ & $52.8 \%$ & $<0.001$ \\
2006 & $30.3 \%$ & $55.5 \%$ & $<0.001$ \\
2007 & $35.7 \%$ & $52.5 \%$ & $<0.001$ \\
$\begin{array}{l}\text { Complete } \\
\begin{array}{l}\text { 3 years follow- } \\
\text { up Complete } \\
\text { diabetes follow- }\end{array} \\
\text { up in all 3 years }\end{array}$ & $26.0 \%$ & $<0.001$ \\
\hline
\end{tabular}

*Complete diabetes follow-up was defined as performing of blood pressure measurement, $\mathrm{LDL}$, microalbumin, and $\mathrm{HbA} 1 \mathrm{C}$ tests and fundoscopy at least once during calendric year.

professionals, to achieve optimal control. From a systemwide perspective, the efforts required to achieve good control among diabetic patients require vast resources from health care systems that are increasingly trying to improve their cost effectiveness.

In our study patients who were provided supplementary structured nursing follow-up in addition to the standard medical care were more likely to achieve complete diabetes maintenance care. There was no difference in systolic blood pressure levels between the groups, and no significant difference in HbA1c levels was observed. LDL targets were reached more frequently among those receiving supplementary follow-up in the first year of the study. However this effect did not carry through the three years of follow-up.

Other studies have demonstrated that nurse led interventions can improve cardiac risk factors in high-risk patients [9] and that nurse case managers using a treatment algorithm can improve the number of individuals with control of multiple cardiovascular risk factors [5]. Practice-based nurses accomplished comparable results with GPs regarding clinical parameters, and achieved better patient satisfaction [10] both at the one year of follow-up assessment. It is possible that due to the differences between the groups, that the clinical effects in our study were less significant than the effectiveness of the protocol on the process of diabetes management. It is also possible that, as was concluded by a Chochrane review, the clinical effects of nurse based interventions are only evident for up to 12 months [6].

Patients receiving supplemental nursing follow-up visited their family physician more frequently than did patients in the control group. It is reasonable to assume that this is a marker for the extensive work needed in order to achieve better diabetes control for these patients. It has been found that shorter encounter intervals were associated with faster decrease in blood pressure and earlier blood pressure normalization in diabetic patients [10]. Additionally, frequent primary care provider encounters 
Table 4 Odds ratios of achieving treatment targets comparing nursing follow-up to physician follow-up only

\begin{tabular}{|c|c|c|c|c|c|c|c|c|}
\hline & OR unadjusted \pm SD & p-value & OR model $1 \pm$ SD & p-value & OR model $2 \pm S D$ & p-value & OR model $3 \pm S D$ & $p$-value \\
\hline \multicolumn{9}{|l|}{2005} \\
\hline Complete follow-up & $4.08 \pm 0.40$ & $<0.001$ & $3.87 \pm 0.39$ & $<0.001$ & $1.97 \pm 0.10$ & $<0.001$ & $1.96 \pm 0.10$ & $<0.001$ \\
\hline $\mathrm{HbA1c}$ & $0.86 \pm 0.09$ & 0.160 & $0.85 \pm 0.08$ & 0.097 & $0.89 \pm 0.09$ & 0.266 & $0.91 \pm 0.10$ & 0.383 \\
\hline LDL & $1.44 \pm 0.14$ & $<0.001$ & $1.41 \pm 0.14$ & 0.001 & $1.39 \pm 0.14$ & 0.001 & $1.34 \pm 0.14$ & 0.006 \\
\hline Systolic BP & $0.71 \pm 0.07$ & 0.001 & $0.73 \pm 0.07$ & 0.004 & $0.74 \pm 0.08$ & 0.005 & $0.74 \pm 0.08$ & 0.007 \\
\hline \multicolumn{9}{|l|}{2006} \\
\hline Complete follow-up & $2.87 \pm 0.27$ & $<0.001$ & $2.77 \pm 0.26$ & $<0.001$ & $2.10 \pm 0.21$ & $<0.001$ & $2.13 \pm 0.21$ & $<0.001$ \\
\hline $\mathrm{HbA1c}$ & $0.83 \pm 0.08$ & 0.062 & $0.79 \pm 0.08$ & 0.017 & $0.83 \pm 0.08$ & 0.060 & $0.83 \pm 0.08$ & 0.072 \\
\hline LDL & $1.19 \pm 0.11$ & 0.070 & $1.15 \pm 0.11$ & 0.150 & $1.14 \pm 0.11$ & 0.169 & $1.08 \pm 0.11$ & 0.431 \\
\hline Systolic BP & $0.64 \pm 0.06$ & $<0.001$ & $0.68 \pm 0.07$ & $<0.001$ & $0.68 \pm 0.07$ & $<0.001$ & $0.67 \pm 0.07$ & $<0.001$ \\
\hline \multicolumn{9}{|l|}{2007} \\
\hline Complete follow-up & $1.99 \pm 0.18$ & $<0.001$ & $1.83 \pm 0.17$ & $<0.001$ & $1.41 \pm 0.07$ & $<0.001$ & $1.43 \pm 0.07$ & $<0.001$ \\
\hline $\mathrm{HbA1c}$ & $1.00 \pm 0.09$ & 0.969 & $0.91 \pm 0.09$ & 0.333 & $0.95 \pm 0.09$ & 0.647 & $0.95 \pm 0.10$ & 0.638 \\
\hline LDL & $0.19 \pm 0.11$ & 0.069 & $1.09 \pm 0.10$ & 0.388 & $1.07 \pm 0.10$ & 0.4396 & $1.04 \pm 0.10$ & 0.705 \\
\hline Systolic BP & $0.79 \pm 0.07$ & 0.001 & $0.79 \pm 0.07$ & 0.015 & $0.79 \pm 0.07$ & 0.014 & $0.79 \pm 0.08$ & 0.020 \\
\hline \multicolumn{9}{|l|}{3 years } \\
\hline Complete follow-up & $3.02 \pm 0.42$ & $<0.001$ & $2.60 \pm 0.37$ & $<0.001$ & $2.22 \pm 0.32$ & $<0.001$ & $2.04 \pm 0.31$ & $<0.001$ \\
\hline
\end{tabular}

Model 1 adjusted for age.

Model 2 adjusted for age and number of physician visits.

Model 3 adjusted for age, number of physician visits, low SES, chronic diseases, gender and immigrant status.

were associated with fastest achievement of $\mathrm{HbA1c}$, BP, and LDL cholesterol targets for diabetic patients [11].

\section{Limitations}

The fact that patient allocation to the two groups was not random and that they were dissimilar in many respects, is a major limitation of this study. Patients in the supplementary follow-up group were older and a higher proportion of these patients had additional chronic diseases and they were more likely to be of a lower socioeconomic status. This is probably a reflection of the medical priorities implemented for patient selection. This selection bias may have hidden additional benefits in the nurse follow-up program. On the other hand, this process may also have led to the selection of patients who are more amenable for intervention [12]. Another limitation of the study is the fact that

Table 5 Follow-up results 2005-2007

\begin{tabular}{|c|c|c|c|}
\hline Year & Physician only follow-up (mean \pm SD) & Supplemental nursing follow-up (mean \pm SD) & P-value \\
\hline \multicolumn{4}{|l|}{ HbA1C levels (\%) } \\
\hline 2005 & $7.5 \pm 1.5$ & $7.6 \pm 1.5$ & 0.057 \\
\hline 2006 & $7.3 \pm 1.3$ & $7.5 \pm 1.5$ & $<0.001$ \\
\hline 2007 & $7.2 \pm 1.3$ & $7.2 \pm 1.4$ & 0.402 \\
\hline Complete 3 years follow-up results in 2007 & $7.2 \pm 1.3$ & $7.2 \pm 1.4$ & 0.692 \\
\hline \multicolumn{4}{|l|}{ LDL cholesterol (mg \%) levels } \\
\hline 2005 & $110.0 \pm 30.3$ & $103.7 \pm 29.7$ & $<0.001$ \\
\hline 2006 & $110.8 \pm 30.9$ & $105.7 \pm 28.3$ & $<0.001$ \\
\hline 2007 & $99.9 \pm 30.9$ & $98.6 \pm 28.9$ & 0.371 \\
\hline Complete 3 years follow-up results in 2007 & $100.5 \pm 30.4$ & $94.2 \pm 27.2$ & 0.0003 \\
\hline \multicolumn{4}{|l|}{ Systolic blood pressure $(\mathrm{mm} \mathrm{Hg})$} \\
\hline 2005 & $136.6 \pm 16.4$ & $137.0 \pm 15.4$ & 0.617 \\
\hline 2006 & $134.8 \pm 14.7$ & $136.5 \pm 14.5$ & 0.020 \\
\hline 2007 & $133.8 \pm 14.8$ & $133.8 \pm 13.7$ & 0.933 \\
\hline Complete 3 years follow-up results in 2007 & $133.8 \pm 14.5$ & $133.9 \pm 13.2$ & 0.816 \\
\hline
\end{tabular}


we could not account for clustering due to the manner in which we collected the data.

Multidisciplinary primary care teams have been found to be effective in improving diabetes control among patients [13]. This study represents the transition of an intervention program into daily routine work. In real life, "nurse time" is a limited resource and should be reserved for those patients who will benefit most from it.

Although the patients receiving supplemental nursing follow-up were older, had a higher incidence of chronic diseases as well as being from a poorer socio-economic background, they achieved better measures of process than the control group and had similar outcome results.

\section{Conclusion}

This study indicates an added value to diabetic structured nursing follow-up in improving the process of diabetic care and possibly clinical control in more complex patients.

The results reinforce the importance of targeting professional resources and of the importance of teamwork, between the physicians and nurses in helping diabetic patients maximize the control of their diabetes. Further investigation is required to assess the effectiveness of nurse led programs to increase their impact on targeted patient groups.

\section{Competing interests}

The authors declare that they have no competing interests.

\section{Authors' contributions}

All authors have made substantial contributions to conception and design, involved in drafting the manuscript, read and approved the final manuscript. MS has substantial contribution to data analysis.

\section{Authors' information}

Michal Shani MD MPH is a family physician at the Department of Family Medicine Central District, Clalit Health Service, and at the Department of Family Medicine Sackler Faculty of Medicine, Tel Aviv University, Israel. Sasson Nakar MD, was a family physician and head of the Department of Family Medicine for the Central District of Clalit Health Service. He passed away in May 2013.

Alex Lustman MD MPH is a family physician at the Department of Family Medicine Central District, Clalit Health Service, and at the Department of Family Medicine Sackler Faculty of Medicine, Tel Aviv University, Israel Amnon Lahad MD MPH is a family physician, and head of the Family Medicine Department of the Hadassah Medical School, The Hebrew University, Israel.

Shlomo VInker MD MHA is a family physician at the Department of Family Medicine Central District, Clalit Health Service, and at the Department of Family Medicine Sackler Faculty of Medicine, Tel Aviv University, Israel.

\section{Acknowledgement}

The study is dedicated to our beloved mentor Dr. Sasson Nakar who passed away on May 2013.

The study was funded by The Israel National Institute for Health Policy and Health Services Research'.

\section{Author details}

'Department of Family Medicine Central District, Clalit Health Service, Rehovot, Israel. ${ }^{2}$ Department of Family Medicine Sackler Faculty of Medicine, Tel Aviv University, Tel Aviv, Israel. ${ }^{3}$ Family Medicine Department Hadassah Medical School, The Hebrew University, Jerusalem, Israel.
Received: 3 December 2013 Accepted: 7 August 2014

Published: 29 August 2014

\section{References}

1. Holman RR, Paul SK, Bethel MA, Matthews DR, Neil HA: 10-year follow-up of intensive glucose control in type 2 diabetes. N Engl J Med 2008, 359:1577-1589.

2. Renders CM, Valk GD, Griffin SJ, Wagner EH, Van Eijk JT, Assendelft WJ: Interventions to improve the management of diabetes in primary care, outpatient, and community settings: a systematic review. Diabetes Care 2001, 24(10):1821-1833.

3. Piette JD, Weinberger M, Kraemer FB: Impact of automated calls with nurse follow-up on diabetes treatment outcomes in a Department of Veterans Affairs Health Care System. A randomized controlled trial. Diabetes Care 2001, 24(2):202-208.

4. Aubert RE, Herman WH, Waters J, Moore W, Sutton D, Peterson BL, Bailey CM, Koplan JP: Nurse case management to improve glycemic control in diabetic patients in a health maintenance organization. A randomized, controlled trial. Ann Intern Med 1998, 129(8):605-612.

5. Ishani A, Greer N, Taylor BC, Kubes L, Cole P, Atwood M, Clothier B, ErcanFang N: Effect of nurse case management compared with usual care on controlling cardiovascular risk factors in patients with diabetes: a randomized controlled trial. Diabetes Care 2011, 34(8):1689-1694.

6. Loveman E, Royle P, Waugh N: Specialist nurses in diabetes mellitus. Cochrane Review 2009. [http://onlinelibrary.wiley.com/doi/10.1002/14651858. CD003286/abstract:jsessionid=ADC93499B8E3943A769DDB853E5AEBA8. d01 t03] (accessed at August 10th 2014)

7. Goldfracht M, Porath A: Nationwide program for improving the care of diabetic patients in Israeli primary care centers. Diabetes Care 2000, 23:495-499.

8. Rennert G, Peterburg Y: Prevalence of selected chronic diseases in Israel. Isr Med Assoc J 2001, 3:404-408.

9. Allen JK, Dennison-Himmelfarb CR, Szanton SL, Bone L, Hill MN, Levine DM: Community Outreach and Cardiovascular Health $(\mathrm{COACH})$ Trial: a randomized, controlled trial of nurse practitioner/community health worker cardiovascular disease risk reduction in urban community health centers. Circ Cardiovasc Qual Outcomes 2011, 4:595-602.

10. Turchin A, Goldberg SI, Shubina M, Einbinder JS, Conlin PR: Encounter frequency and blood pressure in hypertensive patients with diabetes mellitus. Hypertension 2010, 56:68-74.

11. Morrison F, Shubina M, Turchin A: Encounter frequency and serum glucose level, blood pressure, and cholesterol level control in patients with diabetes mellitus. Arch Intern Med 2011, 171:1542-1550.

12. Freund T, Gondan M, Rochon J, Peters-Klimm F, Campbell S, Wensing M, Szecsenyi J: Comparison of physician referral and insurance claims data-based risk prediction as approaches to identify patients for care management in primary care: an observational study. BMC Fam Pract 2013, 14:157.

13. Clark CE, Smith LF, Taylor RS, Campbell JL: Nurse-led interventions used to improve control of high blood pressure in people with diabetes: a systematic review and meta-analysis. Diabet Med 2011, 28(3):250-261.

doi:10.1186/2045-4015-3-27

Cite this article as: Shani et al.: Structured nursing follow-up: does it help in diabetes care? Israel Journal of Health Policy Research 2014 3:27.

\section{Submit your next manuscript to BioMed Central and take full advantage of:}

- Convenient online submission

- Thorough peer review

- No space constraints or color figure charges

- Immediate publication on acceptance

- Inclusion in PubMed, CAS, Scopus and Google Scholar

- Research which is freely available for redistribution 